\title{
Tourists Perception and Opinion towards Ecotourism Development and Management in Redang Island Marine Parks, Malaysia
}

\author{
Mohd Rusli Yacob (Corresponding author) \\ Department of Hospitality and Recreation \\ University Putra Malaysia, 43400 UPM Serdang \\ E-mail:mroy@econ.upm.edu.my \\ Alias Radam \\ Department of Management and Marketing \\ University Putra Malaysia, 43400 UPM Serdang \\ E-mail: Alias@econ.upm.edu.my \\ Zaiton Samdin \\ Department of Hospitality and Recreation \\ University Putra Malaysia, 43400 UPM Serdang \\ E-mail: zaisa@econ.upm.edu.my
}

\begin{abstract}
Ecotourism establishment are the merging the environmental conservation and development. The environmental conservation approach is by recognizing the right and influence of people in biological valuable areas, more attention to human and biological preferences. The development approach was link with the environment to generate economic profitability in term of businesses and employment opportunities. This study analyzed the tourist perceptions and opinions towards ecotourism management and development in one of the famous island in Malaysia. The research addresses concentrating on four sections; analyses of tourists profiles and their characteristic of visit; tourists perceptions and opinions on ecotourism resource management; ecotourism resource maintenance; and tourists opinion on implementing of revenue collection. The personal interview has been made with a total of 298 representative respondents available were used in statistical analyses. The results found that tourists have different preferences against their profiles in term of ecotourism resource management and maintenance as well as on revenue implementation. The results provide useful implications on ecotourism resources management in marine park. It is possibly assists park management for their future improvement in managing ecotourism resources and developed integrated management plan of ecotourism development.
\end{abstract}

Keywords: Ecotourism, Marine park, Sustainable development, Tourist preference, Tourist profile, Ecotourism development

\section{Introduction}

\subsection{Marine Parks in Malaysia}

The idea for the establishment of Marine Parks in Malaysia first arose in the 1980s, after it was realized that the marine fisheries resources had experienced a decline. In order to enhance these resources, the protection of coral reef areas was deemed essential. At the moment there are 40 islands, and the surrounding marine waters have been designated as marine parks under the Fisheries Act 1985 (Department of Fisheries, 2001). These islands are grouped into five centres, which are located off the coast at state of Kedah, Terengganu, Pahang, Johor and Labuan, Table 1.

The primary goal of the establishment of marine parks is to provide an area for the protection and conservation of marine resources and habitats, and to function as a management tool, aiding the drive towards sustainability in the fishing industry (Department of Fisheries, 1996). Marine parks are able to contribute to these objectives through the conservation of critical habitats and biodiversity, the prevention of over-fishing, the maintenance of habitat continuity, and the maintenance of essential ecological processes. The benefits of their establishment are felt not only by direct users such as fishermen, but also by a wide range of users who experience increased opportunities as a result. These include nature lovers, tourism operators, researchers and scientists. The marine parks also provide platforms for the sustainable development of the tourism and ecotourism industries.

Insert Table 1 about hereMany authorities realize that promoting marine park areas as ecotourism sites can lead to a greater interest in their use as an ecotourism destination. Marine parks can provide excellent marine-based ecotourism opportunities which, by increasing visitor numbers, may increase an area's economic potential. Recently, 
the number of visitors to marine parks increased significantly on a yearly basis (Figure 1). This trend can become a challenge to the authorities, who must cater for the needs of the tourists and at the same time ensure the ecosystem of the marine park is well preserved. The main attraction of a marine park to visitors is often its coral reefs, which cater mostly for snorkeling and swimming (Mohd Rusli et al., 2008).

Insert Figure 1 about here

\subsection{Concept of ecotourism development}

Ecotourism is defined in different ways by different groups of people and with different agendas. In simplest terms, ecotourism can be described as interpretative tourism where conservation, understanding and appreciation of the environment and cultures visited is sought. Ecotourism focuses on the natural environment and encompasses numerous tourism forms including nature tourism, wilderness tourism, low impact tourism and sustainable tourism.

Ecotourism defined by the International Union for the Conservation of Nature and Natural Resources (IUCN) (Ceballos-Lascurain, 1993) and endorsed by Ministry of Culture, Arts and Tourism in Malaysia (MOCAT) is 'environmentally responsible travel and visitation to relatively undisturbed natural areas, in order to enjoy and appreciate nature, that promotes conservation, has low visitor impact and provides the beneficially active socio-economic involvement of local populations'(MOCAT, 2000).

The International Ecotourism Society (TIES, 1993), previously known as The Ecotourism Society (TES), defines ecotourism as 'responsible travel to natural areas that conserves the environment and improves the welfare of local people'. According to Wearing and Neil (1999), a definition of ecotourism should include four fundamental elements. The first element is the notion of movement or travel from one location to another. In this element, travel should be restricted to protected and undisturbed natural areas because ecotourism focuses on experiencing natural areas. According to Ceballos-Lascurain (1993), protected or undisturbed natural areas are often the 'best guarantee for encountering sustained natural features and attractions'.

The second element is nature-based. 'Ecotourism is travel, often to developing countries, to relatively undisturbed natural areas for study, enjoyment or volunteer assistance that concerns itself with the flora, fauna, geology and ecosystems of an area as well as the people who live nearby, their needs, their culture and the relationship to the land' (Swanson,1992). The third element which must be included in a definition of ecotourism is conservation. According to Butler (1992), ecotourism has emerged as a result of 'increasing global concern for disappearing cultures and ecosystems'. 'Ecotourism has the potential to foster conservation of natural resources by increasing the awareness by people in the importance of the natural resources' (Butler, 1992) and that is why the element of conservation must be included in a definition of ecotourism.

Finally, the fourth element in a definition of ecotourism is an educative role. According to Eagles and Betters (1998), ecotourists express a strong desire to learn about nature on their trips. Great emphasis is placed on the explanation of 'concepts, meaning and inter-relationships of natural phenomena' (McNeely and Thorsell, 1989). Ecotourism is a vehicle to educate the ecotourists to appreciate the importance of natural and cultural conservation.

However, as a result of the various definitions and concepts of ecotourism as discussed above, in this study, the definition of ecotourism will adopt the definition suggested by IUCN and accepted by MOCAT. This definition is "environmentally responsible travel and visitation to relatively undisturbed natural areas, in order to enjoy and appreciate nature, that promotes conservation, has low visitor impact and provides the beneficially active socio-economic involvement of local populations". The concepts and fundamentals of ecotourism can be summarised as follows:

i. Involvement of nature based activities

ii. Ecologically sustainable

iii. Environment educative

iv. Benefit to local people

v. Generates satisfaction to visitors

The purpose of this study is to investigate the visitor's preferences of the ecotourism development in marine parks in Malaysia in order to help develop management policies that enhance ecotourism contribution to sustainable development and conservation in Malaysia. This assessment of the ecotourism development in marine parks in Malaysia is very important in order to realize that development fulfils the requirement of the visitor preferences through the concept of ecotourism. At the same time it is necessary to realize the archiving and monitoring of sustainable ecotourism development and biodiversity conservation in marine parks. 


\subsection{The Study Area}

The Redang Island Marine Park (RIMP) is located in the north-eastern corner of Peninsular Malaysia, off Terengganu's coastline (Figure 2). They consist of 11 islands with a fast-growing popularity for tourism and ecotourism. The RIMP can be further sub-divided into five groups, all of which have been declared as marine parks. These groups are known as: (i) The Redang Island Marine Park (RIMP), (ii) The Perhentian Island Marine Park (PIMP), (iii) The Lang Tengah Island Marine Park (LTIMP), (iv) The Kapas Island Marine Park (KIMP) and (v) The Tenggol Island marine Park (TIMP).

RIMP is situated in the South China Sea and is located an approximately 24.28 nautical miles or 45 kilometres, from the northern state of Terengganu. It is located at latitude of between $5^{\circ} 44^{\prime}$ and $5^{\circ} 50^{\prime}$ north, and a longitude of $102^{\circ}$ 59' east. This marine park comprises the main island of Pulau Redang, which is associated with 8 islets. These are Pinang Island, Lima Island, Ekor Tebu Island, Kerengga Kecil Island, Kerengga Besar Island, Paku Besar Island, Paku Kecil Island and Ling Island. Of these, only Redang Island and 3 islets (Pinang, Lima and Ekor Tebu Islands) are included as part of the RIMP. However, the other islets are still afforded some protection by virtue of their close proximity (Department of Fisheries, 1996).

The main accessibility to RIMP is via boats, ferries and speedboats that depart from the jetties in Kuala Terengganu and Merang. The journey takes about one hour from Kuala Terengganu and about 30 minutes from the Merang Jetty. Alternatively, there are vessel services available from Kuala Besut Jetty, this ride taking about 2 hours to complete. The main jetties of Redang Island are at Kuala Redang River and Pinang Island. Transportation on land takes place on roads and pathways.

\section{Insert Figure 2 about here}

The marine parks of the east coast of Malaysia, including RIMP, constitute a globally important area of coral and fish biodiversity. The coral reefs at RIMP have been cited as some of the most beautiful in the world (MOSTE, 1998). The area of RIMP contains 149 species of coral from a total of 226 species identified in Malaysia, (Harborne, 2000). Most of the species are found around Redang Island. Meanwhile, a total of 209 fish species have been found in the PRMP (Harborne, 2000). The island also has landing and nesting areas for turtles, some of which are protected as turtle sanctuaries under the SEATRU project, including those at Cagar Hutan, Pasir Mak Kepit and Pasir Mak Simpan. Birds of the "layang-layang" species are also seen at Tanjung Gua Kawah and Tanjung Batu Tok Kong.

In terms of the ecotourism facilities and services, there are 16 chalets and resorts in RIMP. There are about 900 rooms of a range of categories, including 252 luxury rooms, and there is a nine-hole golf course available at the island (Mohd Rusli et al., 2008). Camping sites are also available for the more adventurous tourists and backpackers at Teluk Kalong. The Department of Fisheries has also established privatized and commercialized chalets at the marine parks centre at Pinang Island. Activities like snorkeling and scuba-diving are also popular attractions for tourists on the island. Thus, RIMP is becoming an increasingly important ecotourism destination in Malaysia. For example, whilst in 1995 this marine park was visited by just 22,725 tourists, this has increased on a yearly basis, and in 2005 it received more than 123,159 tourists (Table 2). This overwhelming increase in visitor numbers now poses a serious challenge to the parks management, who must cater for the needs of the tourists whilst ensuring that economic concerns, environmental awareness, marine ecosystem protection and conservation are maintained.

Insert Table 2 about here

\section{Methodology}

The questionnaire was administered with the use of an A4 booklet. It was designed so that it was easy for respondents to understand and answer in an accurate and clear manner. The contents of the questionnaire were designed in a simple short form, the wording was clear, and it used typestyles (bold and italic) to make sure it was easy to read and to differentiate (especially the explanation of attributes and levels). A pilot survey was conducted before the actual survey, with the purpose of testing the questionnaire, including checking the choice of wording, the clarity of questions, and avoiding ambiguous questions.

This study applied the face-to-face or personal interview data collection technique. Through this technique, respondents were asked questions regarding the study purpose at the potential site. The selection of survey method should focus and should consider many things, such as the difficulty of the task to be examined, time constraints, budget limitations, and travel distance.

RIMP, which is located 60 miles from the mainland, involved a sample of visitors. In this case, the personal interview was likely to be the best. In addition, it involved the considerable task difficulty of the study, it was better to use personal interview as a data collection technique to make sure information given and gained was meaningful. 
With this technique, the interviewer could highlight and explain the questionnaire, the confidentiality and the purpose of the study. This process can produce high quality data. Thus, this kind of survey method was better than other data collection techniques. The data was collected during the period of May - July 2004. Face-to-face interviews with visitors were made at three main locations on Redang Island, Marine Park Centre, Pasir Panjang, and Berjaya Redang Beach Resort. These specific locations were selected due to visitor availability, time constraints, and accessibility factors.

\section{Results}

\subsection{Visitors Profile}

This section presents the results of the descriptive analysis of respondents' socio-demographic variables such as age, gender, educational level, employment, monthly gross household income and respondent's place of origin. For comparison purposes, the results also include some characteristics of socio-demographics of the overall Malaysian population. Table 3 shows a summary of the results.

The respondents included visitors aged between 18 and over 70 years old; with the mean age of the sample being 34.01. The mean age of sample respondents is close to that of Malaysia's population. In terms of gender, it was found that $63.1 \%$ were males; however, the proportion of males is higher for the sample than in the Malaysian population $(50.6 \%)$. It may have been due to a sampling bias of non-response, as women may have been absent when interviewers approached at study sites.

The respondent educational level had a mean of 3.06; and it was found that many of the respondents (45.6\%) held university degrees. Next came $32.9 \%$ of respondents with secondary school education, and $18.1 \%$ with a professional certificate or diploma qualification. The rest, $3.4 \%$ had only a primary school education.

The respondent employment status is an important variable in this study because it is related to the respondent level of education and to the level of income. Normally, a higher educational level is linked with better employment and higher income. The results found that most of the respondents were in full-time employment, $66.1 \%$; while $14.8 \%$ were full-time students; and $9.1 \%$ performed home duties or were full-time housewives. Meanwhile, respondent unemployment and retirement figures were $5.7 \%$ and $4.4 \%$ respectively. The proportion of full-time employment is higher for the sample than for the Malaysian population. The main reason for this difference is unclear.

The level of monthly gross household income was grouped within four income levels: very high (>RM 9000), high (RM 6001 - RM 9000), medium (RM3001-RM 6000) and low ( $<$ RM 3000). Results show that most respondents $(36.3 \%)$ fell into the medium income category, followed by $27.5 \%$ in the low-income category. The high and very high-income categories were $18.4 \%$ and $17.8 \%$ respectively. This result shows that most of the respondents fell into the medium income category. However, the sample had a higher monthly gross household income than that for the Malaysian population as a whole. This can be explained by the fact that the sample included respondents who were international tourists $(14.4 \%$ of the total sample) whose income was absolutely higher when their currency was converted to Malaysian currency (RM).

Insert Table 3 about here

\subsection{Tourists' Characteristics of Visits}

The results of respondent characteristics on visits are presented in Table 4. The results show the majority of respondents $(56.7 \%)$ were visiting RIMP for the first time, but high percentages $(43.3 \%)$ of respondents were repeat visitors. The mean for the number of times the respondent had visited RIMP was 1.86 where $56.7 \%$ of respondents had come for the first time. Normally, most of the respondents who came frequently to RIMP were not only attracted by the island environment but also came to participate in specific activities such as snorkeling and scuba diving. The results show that $85.6 \%$ of respondents stated that they would visit the RIMP again in future.

This study also asked respondents about their involvement in any marine institutes or environmental organizations'. Membership of a group such as the Ecotourism Society, World Wide Fund for Nature (WWF), Malaysian Nature Society (MNS), an angling club, a scuba diving club or an environmental group is assumed to influence a respondent's opinion, perception and preferences on ecotourism resources management in RIMP. However, the results showed that a vast majority of the respondents $(71.1 \%)$ were not members of any such organization. The rest were members of a marine or environmental organization.

In terms of the place of origin, the international tourists comprised about $14.4 \%$ of the respondents. However, most of the international tourists came from Singapore as supported by the Department of Marine Park. Meanwhile, results show $85.6 \%$ were domestic visitors. The state of Terengganu contributed $12.4 \%$ of visitors and domestic tourists from other states in Malaysia contributed $73.2 \%$. 
Insert Table 4 about here

\subsection{Tourists' perception of ecotourism resource management}

In this section respondent is required to stated their perception rating likert scale from 5 (agree strongly) to 1 (disagree strongly) for the eight statements regarding the ecotourism resources management in RIMP. Respondents were also asked about their perceptions of the ecotourism resources management as follows:

"If the current management practices for marine parks and areas (MPA) and ecotourism facilities and services (EFS) attributes in RIMP were changed, the management of the ecotourism resources could be improved by some of the statements below. Can you tell me how strongly you agree or disagree with each of the following statements"?

The overall result shows that respondents positively agree with all the statements except for the statements 'increase in accommodation price' and 'increase in revenue collection'. The result shows respondents agreeing (71.1\%) and strongly agreeing $(18.8 \%)$ that change will improve accessibility to RIMP. The respondent agrees and strongly agrees with $68.5 \%$ and $21.1 \%$ respectively in improvement in providing interpretive trails. In terms of total responses, $89.9 \%$ of respondents agree and strongly agree to improvement in providing information to educate people. An approximately $57 \%$ and $20 \%$ of respondents agree and strongly agree respectively that changes will give more efficiency in ecological management. The respondent agrees $(55 \%)$ and strongly agrees $1(8.5 \%)$ that changes will reduce the level of congestion in recreational activities and a total of $80.2 \%$ of respondents agree and strongly agree that changes will increase job opportunities for local people.

When respondents were asked about their perceptions regarding the monetary characteristics, 'an increase in accommodation price' and 'an increase in revenue collection', 55\% and $41 \%$ disagreed respectively. These imply that the respondents will not support both statements due to changes in ecotourism resource management in RIMP.

Insert Table 5 about here

\subsection{Tourists' perception on maintenance of ecotourism resources}

In this section, respondents were asked about their perceptions and opinions regarding the current issues in RIMP. These issues relate to the degradation and depletion of ecotourism and marine resources. In the questionnaire, the respondent was asked:

"The current issues in RIMP concern the degradation and depletion of marine resources. Based on the four statements below, how strongly do you agree or disagree that better management is required in order to maintain the sustainable ecotourism, environment and marine resources in RIMP?"

Table 6 shows $68.5 \%$ and $21.1 \%$ of respondents agree and strongly agree respectively, that the management of RIMP should provide a better-integrated management plan. This situation can give better management and planning for each development in the RIMP rather than with the separated jurisdictions and decisions among stakeholders based on their boundaries and scope in the government agencies as their implementations for the development in RIMP. Meanwhile, $55.4 \%$ and $34.9 \%$ of respondents agree and strongly agree respectively, that the park manager is able to provide a better enforcement of rules and regulations. This implementation will not only reduce the degradation and over-exploitation of marine resources but also can secure the resources for sustainable use.

Development and implementation of the interpretation program resulted in the highest support from respondents, compared to other attributes, with $69.8 \%$ and $20.5 \%$ respondents agreeing and strongly agreeing respectively. This implies that respondents believe that this program is one of the important ways to make people understand better, giving them knowledge and information about marine park resources.

The highest percentage of respondents agreed and strongly agreed, with $60.1 \%$ and $34.9 \%$ respectively, about encouraging education and awareness. Respondents believe that education is the best way to achieve the objectives, not only as a value added to people in term of marine parks but it gives a better approach to encourage people regarding the degradation and over-exploitation of ecotourism and marine resources. Then the resources can be maintained for the sustainability of the ecotourism development.

Insert Table 6 about here

\subsection{Tourists' Opinions on Revenue Implementation}

Respondents were also asked about their opinion of the current management practice of revenue collection for RIMP, on the collection of a conservation charge. Each respondent was also asked about their opinion on the future potential charges in relation to the revenue collection strategy. In relation to revenue issues, each respondent was asked four questions. The questions asked were: 
"The current revenue generated in RIMP or in most marine park ecotourism sites in Malaysia is sufficient to cover the most basic costs of operations (construction of infrastructure, administration and enforcement). Based on your opinion, which are the methods of generating revenue that you are strongly agree or disagree to be implemented in RIMP"

The results of tourists' opinions on revenue implementation are shown in Table 7. The current conservation charge in RIMP is RM 5 for adults and half price for children under 12 years old. These charges are applied to both domestic and international tourists. However, a result of the study shows that $44.6 \%$ of respondents agreed and $7.7 \%$ strongly agreed to the park management increasing the current conservation charge. Meanwhile, $26.5 \%$ of respondents disagree with that statement and $18.5 \%$ of respondents gave the answer 'neither agree nor disagree'.

In response to the suggestion of implementing a tax on tour operators, $41.6 \%$ agreed and $5.7 \%$ strongly agreed. However, a high percentage of respondents (34.9\%) disagreed with this suggestion. In the latter case, respondents might have believed that, when the tax charged to tour operators directly or indirectly, was implemented then they might also be faced with an extra charge to visitors. They may also have believed that the tour operators might increase the rate for tour guides which directly affected the visitors' expenses. These reasons contributed to respondents disagreeing with the suggestion of implementing a tax on tour operators.

Like other National Parks in Malaysia, the Department of Forestry has implemented licenses or permits for specific items in National Parks. For example, a camera permit, fishing permits, etc. Kuala Tahan National Parks charge RM 5 and RM 10 for a fishing permit (DWNP, 2005). However, Marine Parks in Malaysia managed by the Department of Fisheries implemented conservation fees only. However, results in this study found that $41.6 \%$ of respondents disagreed and $6.0 \%$ strongly disagreed on the need for a license or permit to be implemented. Only $32.2 \%$ of respondents agreed. Most of the respondents believed any extra charges other than a conservation charge would affect their other expenditure. Thus, they did not agree with the suggestion of implementing a licence or permit for the specific items such as for photography.

However, respondents' gave a positive feedback for charges for specific activities such as scuba-diving, snorkeling etc. The results show that $43.0 \%$ of respondents agreed to such charges. Meanwhile, $33.9 \%$ and $7.0 \%$ of respondents disagreed and strongly disagreed, respectively.

The overall results show that more than $40 \%$ of respondents agreed and $5 \%$ strongly agreed with the four characteristics or suggestions related to increasing revenue collection to RIMP, except for the implementation of a licence or permit. The percentage of respondents giving the answer 'neither agree nor disagree' for all statements was also high, with an average of $16 \%$. This situation is hard to justify. It might be assumed that they did not want to think too much about that particular issue or they just wanted to play fair. However, this result may affect whether a respondent agrees or disagrees on policy implications.

\section{Discussion and Policy Implication}

In this study, data collection has been made by personal interview, with 298 representative respondents used. The respondent socio-economic profiles; age, gender, education, employment and income give the significant profiles compared to Malaysia's population profile.

The percentage results showed that almost half of the samples (43\%) are returning visitors and more than $85 \%$ promised visits to RIMP in future. The contribution of this result are related to tourists past experience. Past experiences influence perceptions, with a satisfactory experience tempting repetition and possibly encouraging more adventurous pursuits. Yong and William (2004) argued that the perception of travel choices and many destinations is conditioned by three important elements: individual preferences, past experiences and hearsay.

Tourists' perception and opinions of ecotourism development and management in RIMP are very important and useful for the Department of Marine Parks for their guide in management and administration. Their perception concentrated on the resource management, resource maintenance and revenue implementation, measured with a likert scale. Results on resource management showed, out of eight characteristics asked, more than $50 \%$ agreed, except for the characteristics that involved money or cost characteristics. The same pattern of results was found in resources maintenance with more than $60 \%$ of respondents agreeing with all characteristics. That kind of direct opinion and perception could be of assistance, or a guide to park managers to improve their management, maintenance and planning in RIMP.

\subsection{Implications of the Socio Economic Benefits}

The result of socio-demographic profiles of the samples in this study has some potential implications which are discussed in this section. First, the mean age of visitors' was 34; it might be possible to say that the age group of the majority of visitors is between 30 and 40 years old. The information suggests the park manager or ecotourism 
operators should have an effective plan that could concentrate on a particular age range, like a particular activity for example; this could maximize the utilization of their limited resources. For example, park managers or ecotourism operators could create specific recreational activities that are suitable for the age range such as combining jungle tracking with rock climbing etc. That can expect a high response rate from this energetic group.

The socio-economic variables also indicate that the people who visit RIMP are mainly from middle-income families. Even though some of the ecotourism operators in RIMP put their efforts into attracting more affluent visitors, visitors are welcome as they ensure environmental sustainability without damage for future use. For example, providing expensive services as a means of limiting the number of visitors will ensure that the environment is not damaged seriously. This can be implemented especially on hiring cost for snorkeling and scuba-diving facilities; such as cost for hiring boat, equipments and cost of lessons, to visitors at the marine park centre in order to avoid too many users using the services at one time.

The result also indicates that, of the visitors in RIMP, nearly half hold a university degree (45.6\%). Thus, most of them are educated visitors. That kind of information is useful especially regarding the information provided, the quality of service provided and the level of satisfaction. Normally, higher educated people have a better gross monthly income and demand more information and knowledge about the environment. Thus, this group normally expects a high quality of services provided and they might assume they would get a better experience from their participation.

\subsection{Implications of the Characteristics of Visits}

The results of visitor characteristics of visit are very important for ecotourism operators for their planning and marketing. Redclift and Woodgate (1997) supported that the social characteristics should be incorporated into decision making and managing process to lead a better management of the ecotourism resources. For example, the results show a high percentage of the sample (43.3\%) had visited the RIMP previously. This implies that there are elements in RIMP that are interesting to them that make them want to visit again and possibly come again in future. The main reason that encouraged visitors to return to RIMP is the anticipation of specific activities such as snorkeling and scuba activities. Such information is very important for the ecotourism operators and ecotourism planners for marketing their products and developing marketing strategies. Moreover, results show that $18 \%$ of the sample had visited RIMP more than three times. Thus, ecotourism operators can reduce their expenditure by focusing their promotion specifically to target selected groups only. In that way, they can reduce their expenditure for promotion and marketing.

Another important visitor characteristic of visits is place of origin. Results indicate that international visitors contribute only $14.4 \%$ of the samples and most of them are from Singapore. This information is very important for ecotourism operators to make some efforts to increase their marketing or promotion in overseas countries like Germany, Britain, the United States, Canada and Australia, for example, as these are the countries with the greatest number of visitors to the region.

\subsection{Implications of Perceptions and Opinions of Ecotourism Development}

Results of visitors' perceptions and opinions of ecotourism resources in RIMP show that the majority of the people sampled agreed and strongly agreed with the improvements suggested, as described in Table 7: namely that accessibility to RIMP should be improved; there should be improvements in provision of interpretive trails; improved provision of information; improved efficiency in ecological management; reduced congestion levels; and improved employment opportunities for local people. Such information may assist and guide the Department of Marine Parks in their management and planning. However, all the improvements discussed above are quite general. More information that is specific can be provided in term of the level of improvement for each characteristic in further analysis. For example, the tourists perception also shows that the majority of the sample agreed and strongly agreed (82\%) with increasing the employment opportunities for local people. However, determination for how much increase in employment could be examined in further analysis.

In term of visitors' perceptions on maintenance of ecotourism resources in RIMP, the majority of the sample gives a high positive support to the four main characteristics as follows:

i. Provide a better integrated management plan

ii. Enforcement with rules and regulations

iii. Develop and implement interpretive programme and

iv. Encourage education and awareness 
However, that kind of information could be classified as general information of visitors' perceptions for each characteristic for the maintenance of ecotourism resources in RIMP. The visitors believed that they are very important characteristics for implementation in order to maintain the ecotourism resources to ensure that resources are sustained either for short- or long-term use.

The results of visitors' opinions on revenue implementation in RIMP shows that visitors strongly agreed and agreed (Table 7) about three types of characteristics: increase the current conservation charge, implementing a tax on tour operators and charges for specific activities. However, visitors did not agree with implementing a licence or permit (such as for fishing and photography). Visitors positively agreed and strongly agreed (52\%) to increase the current conservation charge of RM5 per entrance. Thus, the Department of Marine Parks should consider increasing the current conservation charge. By increasing the conservation charge, their maintenance, management and administration costs for the marine park can be supported.

\section{Conclusion}

The objective of the study is to investigate the tourist perception on ecotourism management and development. Thus, tourist perceptions can produce information, which is at least as useful as basic monitoring for marine ecosystem management, quality and development. Data coming from perception analysis can be useful for further analysis such as scenario building and simulation model (walker et al., 2002). In fact, we already know that the effective management and ecotourism development should take into consideration of the tourist perception, motivation, preferences in order to fulfill their satisfaction and experiences. Orams (1995) argues that ecotourism management strategies should attempt to move ecotourism experiences beyond mere enjoyment to a more active role which incorporates learning, attitude and behavioral change.

The tourist preferences and perception of environmental problems such as in marine parks can be a better basis for planning and management; so that a management approach can be successful, if the dialogue between managers and stakeholders, supporting and sharing decisions is encouraged (Tress and Tress, 2003). However, if park managers are to include public input as guidance in managing ecotourism resource, they have to consider how tourist perceptive themselves as affecting resource and uses. A different perception can be due to marine park related attitudes, but also to the characteristics of tourist profile that frequent ecotourism destination. In this respect, we need to better identify tourist profile, as we showed that the place of residence can explain some relevant differences in resource awareness among tourists. However, the relationship among the tourist profile and their perception is not cover in this study, and perhaps should be considered for further study.

The effective planning, development and management of the ecotourism should be refers to the concept and fundamental of ecotourism; involvement of nature based activities, ecologically sustainable, environment educative, benefit to local people and generates satisfaction to visitors (Fennell, 1999). Thus, through the elicited of tourist preferences on ecotourism resource attributes which related to the concept and fundamental of ecotourism are greatly necessary. By determine how much tourists prefers for each ecotourism attributes, perhaps contain a meaningful information and could assists the park manager decision making process towards a sustainable ecotourism development in marine parks, Malaysia.

\section{References}

Butler, R. (1992). Ecotourism: Its Changing Face and Evolving Philosophy. Paper Presented at the International Union for Conservation of Nature and Natural Resources (IUCN), World Congress on National Parks and Protected Areas, Caracas, Venezuela.

Ceballos-Lascurain, H. (1993). Ecotourism as a Worldwide Phenomenon. Ecotourism: A Guide for Planners and Managers. K. Lindberg and E. Hawkins. Vermont, USA, The Ecotourism Society: 12-14.

Department of Fisheries. (1996). Marine Parks of Malaysia Annual Report. Kuala Lumpur, Malaysia.

Department of Fisheries. (2001). Annual Fisheries Report. Kuala Lumpur, Malaysia.

Department of Fisheries. (2003). Annual Fisheries Report. Kuala Lumpur, Malaysia.

DWNP. (2005). Department of Wildlife and National Park, Malaysia, http://www.wildlife.gov.my/i_eco_tn.htm\#satu, Access in August 2006.

Eagle, J. and D. Betters. (1998). The Endangered Species Act and Economic Values: A Comparison of Fines and Contingent Valuation. Ecological Economics 26: 165-171

Fennell, D. A. (1999). Ecotourism: An Introduction. London, Routledge. 
Harborne, A., D. Fenner, A. Barnes, M. Beger, S. Harding and T. Roxburgh. (2000). Status Report on the Coral Reefs of the East Coast of Peninsula Malaysia. Report Prepared to Department of Fisheries Malaysia, Kuala Lumpur, Malaysia.

McNeely, J. and J. Thorsell. (1989). Jungles, Mountains and Islands: How Tourism Can Help Conserve the Natural Heritage. World Leisure and Recreation 31(4): 29-39.

MOCAT. (2000). National Ecotourism Plan. Kuala Lumpur, Malaysia, Ministry of Culture, Arts and Tourism: Volume 1-5.

Mohd Rusli Y., Ahmad S. and Alias R. (2008). How Much Does Ecotourism Development Contribute to Local Communities? An Empirical Study in a Small Island. The ICFAI Journal of Environmental Economics, 4(2):54 - 67

Mohd Rusli Y., Ahmad S., Alias R. and Wahidin K (2008). Estimating the Conservation Value for Ecotourism in Marine Parks: A Contingent Valuation Approach. Proceedings of the $2^{\text {nd }}$ International Colloquim on Tourism and Leisure, Chiang Mai Thailand 5-8 May 2008. ISBN: 978-1-60643-451-2

MOSTE. (1998). National Policy on Biological Diversity. Kuala Lumpur, Malaysia, Ministry of Science, Technology and the Environment: 27.

Orams, M. B. (1995). Towards a more desirable form of Ecotourism. Tourism Management,(16) 3-8.

Redclift and Woodgate. (1997). In: M. Redclift and G. Woodgate, Editors, The International Handbook of Environmental Sociology, Edward Elgar, Cheltenham, UK.

Redclift, M., Woodgate, G. (1997). The International Handbook of Environmental Sociology. Edward Elgar, Cheltenham, UK

Swanson, M. A. (1992). Ecotourism: Embracing the New Environmental Paradigm. Caracas, Venezuela, International Union for Conservation of Nature and Natural Resources (ICUN) IV World Congress on National Parks and Protected Areas.

TIES. (1993). The International Ecotourism Society. Ecotourism Guidelines for Nature Tour Operators. Burlington, VT, USA, The International Ecotourism Society.

Tress, B., Tress, G. (2003). Scenario Visualization for Participatory Landscape Planning a Study from Denmark. Landscape Urban Planning 64, 161-178

Walker, B., Carpenter, S., Anderies, J., Abel, N., Cummings, G. S., janssen, M., Lebel, L., Norberg, J., Peterson, G., Pritchard, R. (2002). Resilience management in Social Ecological Systems: a Working hypothesis for a Participatory Approach. Conservation Ecology, 6(1) 14

Wearing, S. and J. Neil. (1999). Ecotourism: Impacts, Potentials and Possibilities, Butterworth Heinman, Oxford, United Kingdom.

Yong, K.S and William, C. G (2004). Perceptions in International Urban Research: An Analysuis of Travelers to Seoul, Korea, Journal of Travel Research, 43 (39-45).

\section{Acknowledgement}

We want to thanks to Department of Marine Parks, especially Redang Island Marine Park manager and their staffs for the support and co-operation during this study. A special thanks to our research fellows for his constructive comments and suggestions of the earlier version of this paper.

Table 1. Groups of Marine Parks and Marine Parks Centre in Malaysia

\begin{tabular}{|l|c|c|c|}
\hline \multicolumn{1}{|c|}{ Location } & State & No. of Islands & Year Operational \\
\hline Redang Island Marine Parks & Terengganu & 11 & 1990 \\
\hline Payar Island Marine Parks & Kedah & 4 & 1988 \\
\hline Tioman Island Marine Parks & Pahang & 9 & 1995 \\
\hline Mersing Marine Parks & Johor & 13 & 1994 \\
\hline Labuan Marine Parks & Sabah & 3 & 1996 \\
\hline
\end{tabular}


Table 2. Number of Visitors to Redang Island Marine Park

\begin{tabular}{|c|c|c|c|c|c|}
\hline Year & $\begin{array}{c}\text { International } \\
\text { Visitors }\end{array}$ & $\mathbf{\%}$ & $\begin{array}{c}\text { Domestic } \\
\text { Visitors }\end{array}$ & $\mathbf{\%}$ & Total \\
\hline 1995 & 4,035 & 18 & 18,690 & 82 & 22,725 \\
\hline 1996 & 7,755 & 22 & 26,988 & 78 & 34,743 \\
\hline 1997 & 5,940 & 16 & 30,258 & 84 & 36,198 \\
\hline 1998 & 7,544 & 22 & 26,922 & 78 & 34,466 \\
\hline 1999 & 7,559 & 16 & 39,449 & 84 & 47,008 \\
\hline 2000 & 9,244 & 18 & 43,390 & 82 & 52,634 \\
\hline 2001 & 8,041 & 11 & 65,539 & 89 & 73,580 \\
\hline 2002 & 7,563 & 12 & 56,263 & 88 & 63,826 \\
\hline 2003 & 4,565 & 06 & 71,654 & 94 & 76,219 \\
\hline 2004 & 31,251 & 22 & 111,225 & 78 & 142,476 \\
\hline 2005 & 24,296 & 20 & 98,863 & 80 & 123,159 \\
\hline
\end{tabular}

Table 3. Tourist' Profile $(\mathrm{N}=298)$

\begin{tabular}{lrc}
\hline \multicolumn{1}{c}{ Variables } & \% & Malaysian population * \\
\hline Age (in years) & 34.01 & 33.50 \\
Gender & & 50.6 \\
Male & 63.1 & NA \\
$\quad$ Female & 36.9 & \\
Education level & & \\
$\quad$ Primary school & 3.4 & \\
Secondary School & 32.9 & \\
Professional Cert./Diploma & 18.1 & \\
University Degree & 45.6 & \\
Employment status & & \\
Full-time employment & 66.1 & \\
Unemployed & 5.7 & RM3071.6 \\
Home duties & 9.1 & \\
Full-time student & 14.8 & \\
Retired & 4.4 & \\
Monthly gross household income & & \\
Low (Below RM 3000) & 27.5 & \\
Medium (RM3001-RM6000) & 37.3 & \\
High (RM 6001-RM 9000) & 35.2 & \\
\hline
\end{tabular}

*: Based on Malaysian socio-economics profiles from World Bank Development Indicators, CD-ROM 2002 reference with monthly gross household income is based on household income per capita, MYR36,860.

Table 4. Characteristics of visits

\begin{tabular}{lc}
\hline Definitions and coding & $\%$ \\
\hline Number of times visited RIMPs & 56.7 \\
First time visit & 26.2 \\
Second time visit & 13.1 \\
Third to Fifth times visit & 5.0 \\
More than six times visit & \\
Will visit RIMP in future & 85.6 \\
Will visit again & 14.4 \\
Will not visit again & \\
Member of marine institution or environmental organization & 28.9 \\
Members & 71.1 \\
Non-members & \\
Place of origin & 14.4 \\
International tourists & 12.4 \\
Domestic visitors (Terengganu) & 73.2 \\
Domestic visitors (others) & \\
\hline
\end{tabular}


Table 5. Tourists' perception on ecotourism resources management

\begin{tabular}{|c|c|c|c|c|c|}
\hline \multirow[t]{2}{*}{ Questions } & \multicolumn{5}{|c|}{ Visitors' $(\mathrm{N}=289)(\%)$} \\
\hline & $\begin{array}{l}\text { Agree } \\
\text { Strongly }\end{array}$ & Agree & $\begin{array}{c}\text { Neither agree } \\
\text { or disagree }\end{array}$ & Disagree & $\begin{array}{c}\text { Disagree } \\
\text { strongly }\end{array}$ \\
\hline Improvement in accessibility & 18.8 & 71.1 & 8.4 & 1.0 & 0.7 \\
\hline Improvement in providing interpretive trails & 21.1 & 68.5 & 7.4 & 3.0 & 0 \\
\hline Improvement in providing information to educate people. & 36.2 & 53.7 & 7.0 & 2.3 & 0.7 \\
\hline Increase in accommodation price & 3.7 & 22.1 & 25.5 & 41.9 & 6.7 \\
\hline More efficiency in ecological management & 20.5 & 57.7 & 9.4 & 8.7 & 3.7 \\
\hline Reduce the level of congestion in recreational activities & 18.5 & 55.4 & 10.7 & 13.8 & 1.7 \\
\hline Increase opportunity of jobs to local people & 23.8 & 56.4 & 13.8 & 4.7 & 1.3 \\
\hline Increase in revenue collection & 0.3 & 16.4 & 18.8 & 55.0 & 9.4 \\
\hline
\end{tabular}

Table 6. Tourists' perception on maintenance of ecotourism resources

\begin{tabular}{|c|c|c|c|c|c|}
\hline \multirow[t]{2}{*}{ Questions } & \multicolumn{5}{|c|}{ Visitors' $(\mathrm{N}=289)(\%)$} \\
\hline & $\begin{array}{l}\text { Agree } \\
\text { Strongly }\end{array}$ & Agree & $\begin{array}{l}\text { Neither } \\
\text { agree or } \\
\text { disagree }\end{array}$ & Disagree & $\begin{array}{c}\text { Disagree } \\
\text { strongly }\end{array}$ \\
\hline Provide a better integrated management plan & 21.1 & 68.5 & 6.4 & 3.7 & 0.3 \\
\hline Better enforcement with rules and regulations & 34.9 & 55.4 & 7.7 & 1.3 & 0.7 \\
\hline Develop and implement the interpretation program & 20.5 & 69.8 & 7.7 & 1.7 & 0.3 \\
\hline Encourage education and awareness & 34.9 & 60.1 & 4.7 & 0 & 0.3 \\
\hline
\end{tabular}

Table 7. Tourists' opinion on revenue implementation in RIMP

\begin{tabular}{|c|c|c|c|c|c|}
\hline \multirow[t]{2}{*}{ Questions } & \multicolumn{5}{|c|}{ Visitors' $(\mathrm{N}=289)(\%)$} \\
\hline & $\begin{array}{l}\text { Agree } \\
\text { Strongly }\end{array}$ & Agree & $\begin{array}{l}\text { Neither } \\
\text { agree or } \\
\text { disagree }\end{array}$ & Disagree & $\begin{array}{l}\text { Disagree } \\
\text { strongly }\end{array}$ \\
\hline Increase the current conservation charge & 7.7 & 44.6 & 18.5 & 26.5 & 2.7 \\
\hline Implementing tax on tour operators & 5.7 & 41.6 & 16.8 & 34.6 & 1.3 \\
\hline $\begin{array}{l}\text { Implementing licenses or permit; e.g. fishing and camera } \\
\text { permits }\end{array}$ & 5.4 & 32.2 & 14.8 & 41.6 & 6.0 \\
\hline $\begin{array}{l}\text { Charge for specific activity such as scuba-diving, snorkeling } \\
\text { etc. }\end{array}$ & 2.7 & 43.0 & 13.4 & 33.9 & 7.0 \\
\hline
\end{tabular}

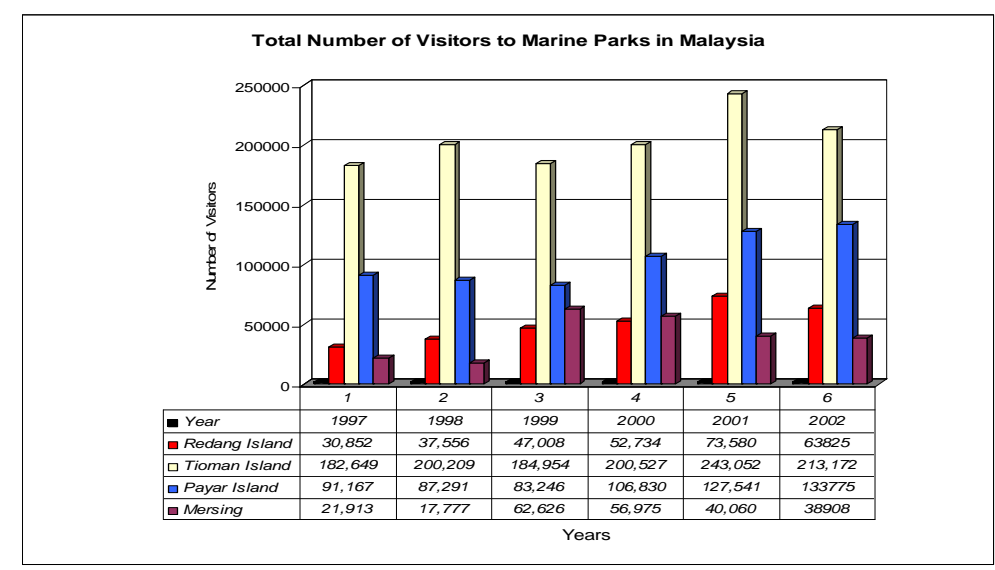

Figure 1. Total Numbers of Visitors to Marine Parks in Malaysia

Source: Department of Fisheries 


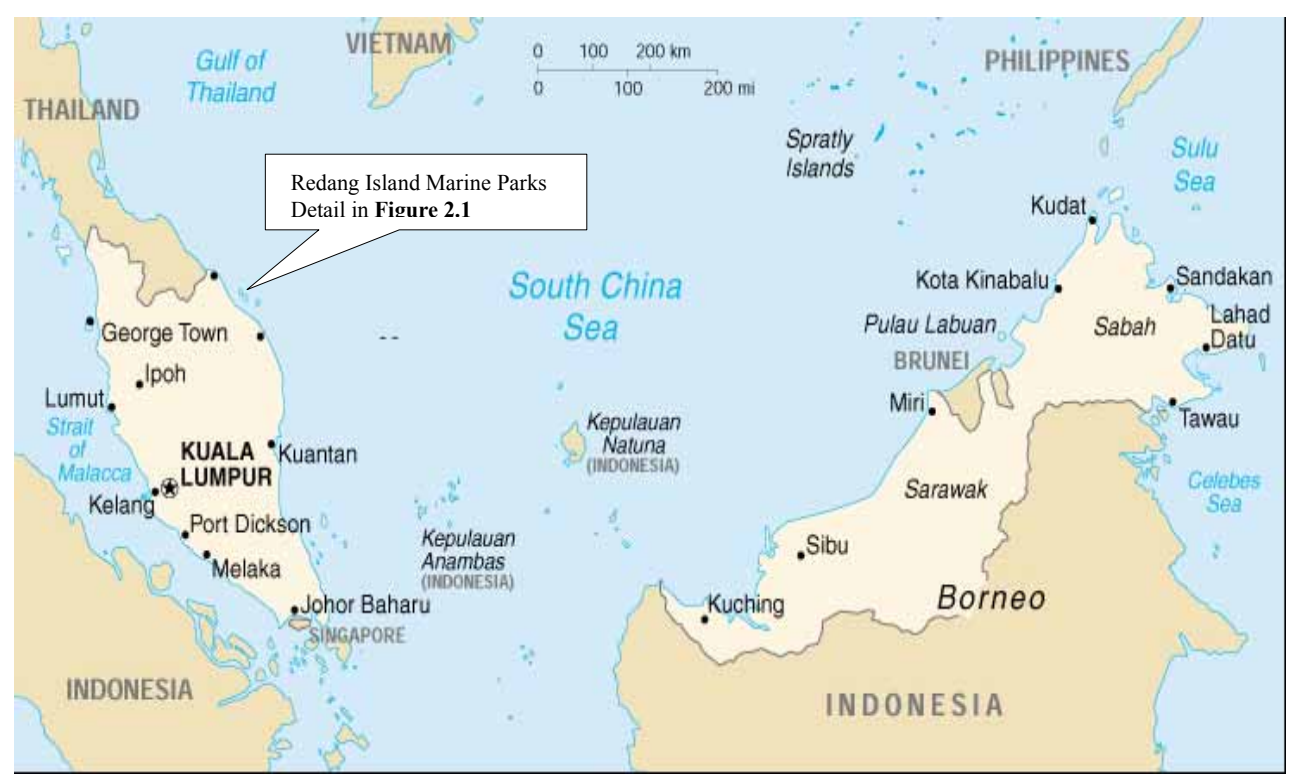

Figure 2. The Geographical Location of Malaysia and Redang Island Marine Parks

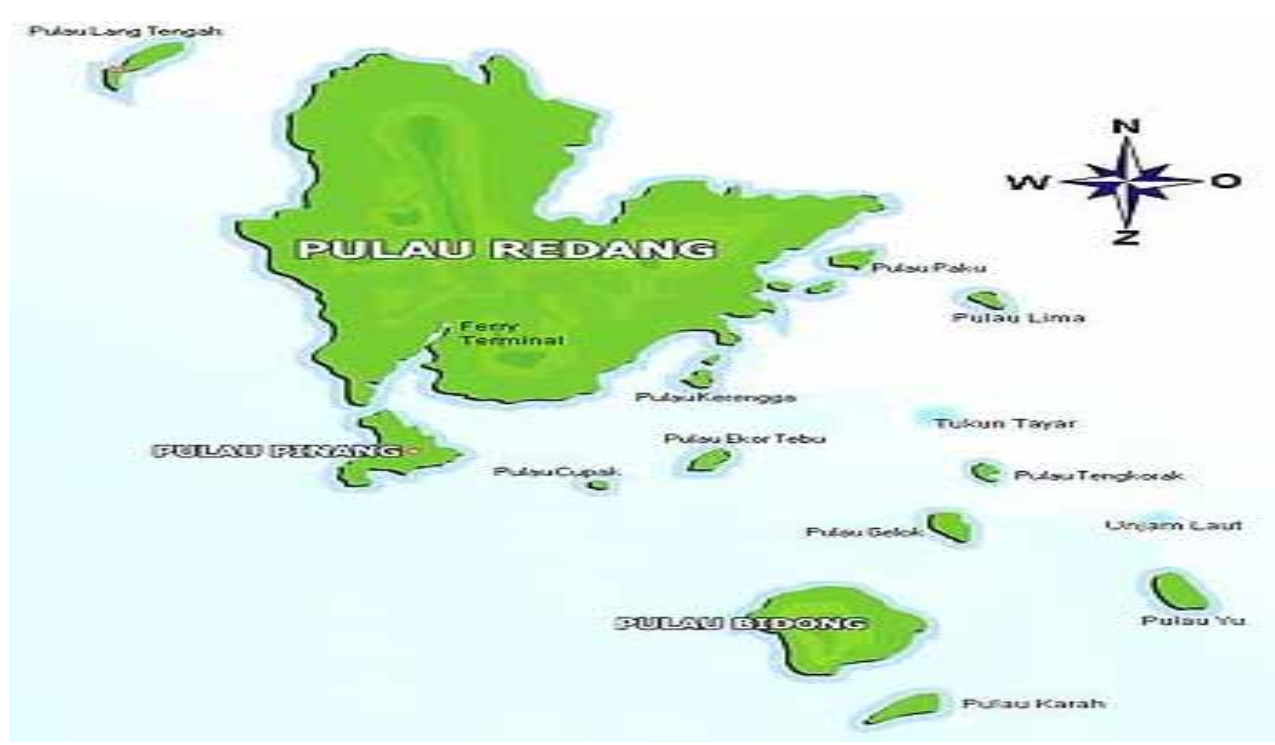

Figure 2.1 Location of the Redang Island Marine Park 